\title{
MEASUREMENT OF RESIDUAL STRESSES IN AI-SiC COMPOSITES BY NEUTRON AND X-RAY DIFFRACTION
}

\author{
中性子回折およびX線回折による A $1-\mathrm{S}$ i C 複合材料の残留応力測定 \\ C. BRAHAM ${ }^{1}$, A. LODINI ${ }^{2}$, J.P. BONNAFE ${ }^{3}$, J.L. LEBRUN ${ }^{1}$, \\ M. PERRIN ${ }^{4}$ and B. CHENAL ${ }^{5}$ \\ ${ }^{1}$ LM3, URA CNRS 1219, ENSAM, 151 Bd de l'Hopital 75013 PARIS France \\ ${ }^{2}$ Lab. Materiaux, ESIEC, 51000 REIMS France \\ ${ }^{3}$ AEROS PATIALE, DSSS, 78130 Les Mureaux France \\ ${ }^{4}$ Lab. L. BRILLOUIN, CEA-CNRS, CEN Saclay, 91191 Gif-sur-Yvette France \\ ${ }^{5}$ C.R.V. Pechiney, B.P. 27, 38340 Voreppe France
}

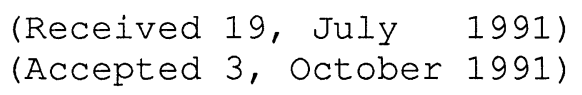

\begin{abstract}
The determination of macroscopic and microscopic residual stresses, their influences and their variations have to be taken into account to study the behaviour of short fiber reinforced metal matrix composite behaviour under external applied stresses. X-ray and neutron diffraction applied to matrix and reinforcement made it possible to give a good evaluation of these stresses. A great care is needed for the evaluation of the stress free parameter $\mathrm{a}_{0}$ especially in the case of stress and chemical composition gradients. First order thermal stresses similar in two $\mathrm{Al}-\mathrm{SiC}$ and $\mathrm{Al}$ specimens but in the previous one, second order stresses are very high.
\end{abstract}

Key words : Residual stresses, Neutron diffraction, X-ray diffraction, Composite, Al-SiC

\section{INTRODUCTION}

Metal matrix composite (MMC) is a combination of a metal (mainly aluminium, magnesium and titanium) and short or long fiber reinforcement (boron, carbon, tungsten of oxide and carbide for short fibers), supposed to combine the advantages of each component. In this study, only aluminium alloy matrix composite reinforced with silicon carbide whiskers ( $\mathrm{SiC}$ ) will be discussed.

Mechanical and physical properties for these materials have already been studied. ${ }^{1}$ An increase of the reinforcement rate will lead to an increase of Young's modulus, of yield stress and failure stress, an increase of density, but at the same time, to an increase of brittleness and a decrease of shock behaviour. Thermal dilatation coefficient and thermal conductivity will also decrease but friction properties are improved. Nevertheless, MMC properties are not only due to reinforcement rate and reinforcement nature but also to matrix metal quality and interface properties. 


\section{MECHANICAL CHARACTERIZATION AND BEHAVIOUR}

Dislocation density determinations in MMC (SiC/Al type) foresee large values mainly due to thermal stresses. ${ }^{2}$ Thus, thermal treatment stresses are influenced by strong connection at the matrix-fiber interface, by high temperature strengthening and by the dissymmetry between dilatation coefficients.

Mechanical characteristics of short fibers reinforced MMC can be obtained with the same procedures than metallic materials. The results can be correlated to calculated ones from constituent values. Many authors ${ }^{3}$ have found a good approximation using a simple "proportional law" or using more complex laws, such as TsaiHalpin law which integrate corrective factors taking into account reinforcement geometry, interface strength, and so on. Nevertheless, no law has been revealed as universal law for every MMC types.

Concerning residual stress determination in MMC, results are not very numerous, especially with $\mathrm{X}$-ray diffraction technique mainly used for matrix measurements. ${ }^{4}$ However, studies in which residual stresses are determined in the reinforcement as well as in the matrix ${ }^{5}$ show that when there is no external loading, matrix residual stresses were tensile stresses and fibers residual stresses were compressive stresses. Such results have been predicted by theoretical approach based on a calculated comparison between material with and without reinforcement. ${ }^{6}$ A recent study $^{7}$ has explained the difference between tensile stress value and compressive stress value by the existence of pseudo-macrostresses which are not taken into account by conventional methods. Finally, for some surface mechanical treatments, surface residual stresses appear to be tensile stresses or compressive stresses in the two phases (matrix and fibers). In this case, the equilibrium is obtained under the surface with different distribution profiles.

For the neutron diffraction, recent parallel work in different laboratories has made this technique now available in most countries for the investigation in metal matrix composite. For example, Withers and $\mathrm{al}^{8}{ }^{8}$ studied the internal stresses in a short fiber $\mathrm{SiC}$ in metal matrix $\mathrm{Al}$ $\mathrm{Al}_{2} \mathrm{O}_{3}$ and the influence of 5 and $10 \%$ by volume of SiC. Allen and al. ${ }^{9}$ studied the residual and load induced strains in composite of $20 \%$ by volume in whiskers $\mathrm{SiC}$ and $2014 \mathrm{Al}$ matrix. Lilholt and al. ${ }^{10}$ studied the internal stresses in $\mathrm{Al}-\mathrm{SiC}$ composites under thermal treatments.

\section{EXPERIMENTAL PROCEDURE}

Various methods are commonly used to determine residual stresses. The X-ray diffraction method has been chosen because of its capability to be non destructive at the surface, to give information at macroscopic and microscopic level in the matrix as well as in reinforcement. This method uses interatomic spacing $d_{\text {hkl }}$ of a family of planes as strain gauge. Strain measurement $\varepsilon=\Delta \mathrm{d} / \mathrm{d}_{0}$ is related to diffraction angle displacement $2 \theta$ according to Bragg's law : at macroscopic scale, uniform deformation is translated in a simple diffraction peak shift, at microscopic scale, variations of $d$ around mean value lead to peak broadening. We have to point out that residual stresses determined at macroscopic level by X-ray diffraction are considered as the sum of residual stresses of first order ( $\sigma \mathrm{I}$ $=$ main grains scale) and of macroscopic residual stresses of the second order $(\sigma \mathrm{IIM}=$ grain scale). It can explain why some differences can be found between the X-ray diffraction method and other mechanical methods for stress determination. Concerning MMC, we have to notice that this material is a two-phase material (or can be considered as such), and X-ray diffraction method only gives results in one phase at the time. Hence we have to integrate residual macro- 
stresses in each phase to make a good comparison with other results and to evaluate the validity of X-ray determination.

Neutron diffraction is also a promising non destructive technique which can give complementary information about internal stresses. The analyses are carried out with the G 42 spectrometer which is a two axis spectrometer with the Eulerian cradle, using neutrons coming from one of the cold guide of the Orphée reactor with which we work in conventional condition with constant wavelength. As for X-ray diffraction, the precise evaluation of interplanar distance is needed to evaluate the deformation of interplanar distance by mean of Bragg's law. The differentiation of Bragg relation and the fact that an important value of $\theta$ angle leads to large analysed volume obliged us to work with a $2 \theta$ angle of $90^{\circ}$.

We use a generalised method. The homogeneous and isotropic solid with an elastic deformation is characterized by a tensor $\varepsilon$. If we suppose, the spheric volume element with an ellipsoid shape. $\varepsilon_{\phi \psi}$ is determined using the formula:

$\varepsilon_{\phi \psi}=a_{1}^{2} \varepsilon_{x}+a_{2}^{2} \varepsilon_{y}+a_{3}^{2} \varepsilon_{z}+2 a_{1} a_{2} \varepsilon_{x y}+2 a_{1} a_{3} \varepsilon_{y z}+2 a_{1} a_{3} \varepsilon_{x z}$

An ellipsoid regression involves the evolution of $\varepsilon_{\phi \psi}$ with an important number of experimental value, typically 20 points. The main strains are determined by a diagonalization of this matrice. It is then possible to determine the main stresses with the generalized Hooke law.

In a preliminary work, it was interesting to measure the repartition of the stresses by this generalized method and then to compare this method to that of the finite elements. For this purpose we have used the experimental set up of SCHMANK and KRAWITZ. This specimen in an aluminium alloy is a $U$ shape with a square section of $25.4 \times 25.4 \mathrm{~mm}^{2}$. It is compressed in two directions. The displacement is $\Delta x=\Delta y=$ $12 \mathrm{~mm}$. In neutron diffraction, the analysed volume is $3 \times 3 \times 3 \mathrm{~mm}^{3}$.

We use a wavelength of $3.29 \AA$ and the Bragg plane (111). We determine the diffraction peak with 40 experimental values every 0.05 degree. We calculate the function of the peak with a gaussian profile. The parameters are obtained with the statistical method. Because of the great number of experimental points necessary for the calculation of the regression, the measuring time is of about 2 weeks.

Figure 1 shows the evolution of the main stress $\sigma_{\mathrm{xx}}=\mathrm{f}(\mathrm{z})$ for the neutrons and the finite element method. For stress values between 0 and $320 \mathrm{MPa}$ we obtain a difference inferior to 80 MPa.

\section{EXPERIMENTAL RESULTS AND DIS- CUSSION}

Two specimens are analysed:

- the first one, reference 6 , is a metal matrix composite (MMC). The matrix is a 2024 aluminium alloy and the reinforcement (25\%) is a Silicon Carbide whiskers (SiC);

- the second one, reference 4, is a 2024 aluminium alloy.

In all cases, the dimensions of the specimens are $20.3 \mathrm{~mm}$ in diameter and $50 \mathrm{~mm}$ in length. They are issued from extruded bar. The heat treatment is a water quenching after a solution annealing at $480^{\circ} \mathrm{C}$, followed by a liquid nitrogen quenching and a natural aging.

At first, for MMC specimen, in the aluminium matrix, 3D analysis has been carried out to determine the orientation of the principal stresses directions. The results show that these directions respect the specimen symmetry. This conclusion is not affected by the stress free lattice parameter value $a_{0}$. Thus we can use the monodimensional method for the different following analysis. 
For this method, as described above, the a for the unstressed specimen $\left(a_{0}\right)$ is primary importance. The value obtained by neutron diffraction, on a powder sample taken from the whole specimen is $\mathrm{a}=4.0489 \AA$. However the utilization of this value has given uninterpretable results. A second experiment has been done : a small quantity of powder has been taken at a precise radius (at $\mathrm{r} \pm 0.05 \mathrm{~mm}$ ) and analysed by $\mathrm{X}$-ray diffraction (because of the too small volume for neutron analysis). The results (Fig. 2) reveal a constant value of $a_{0}$ over the most part of the cylinder but shows a strong variation near the surface. This evolution should come

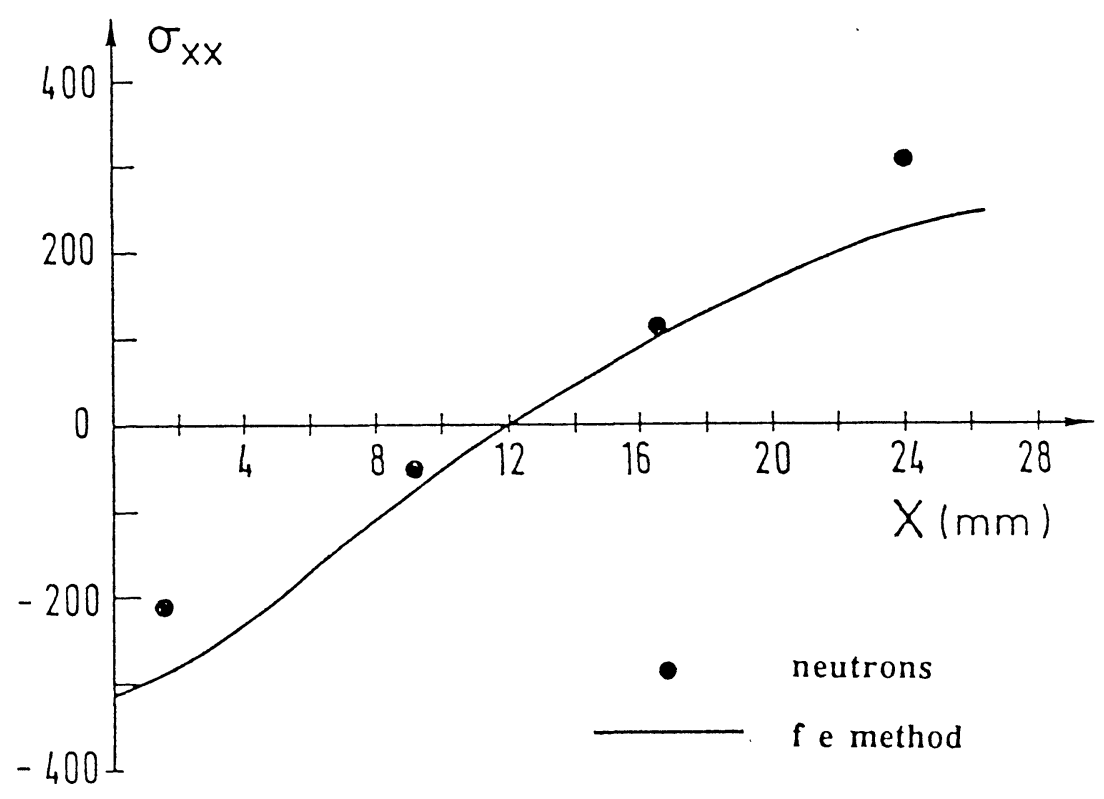

Fig. 1. Evolution of the main stress $\sigma_{x x}=f(z)$ in aluminium specimen.

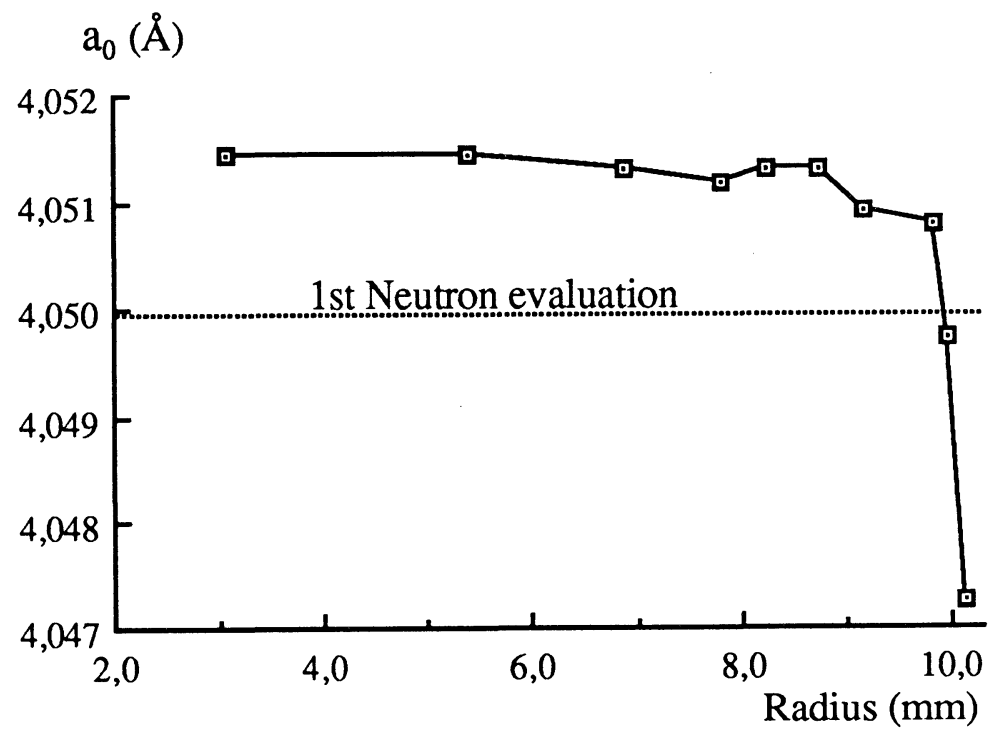

Fig. 2. Evolution of the $a_{0}$ as a function of the radius. 
from a variation in $\mathrm{Mg}$ (and also $\mathrm{Cu}$ ) content in solution in the $\mathrm{Al}$ matrix. The first a value measured by neutron lies between the extreme. The use of the two extreme values gives a difference as large as $200 \mathrm{MPa}$ on $\sigma_{\mathrm{z}}, \sigma_{\Theta}$ and $\sigma_{\mathrm{r}}$
(Fig. 3).

The neutron diffraction results obtained for the aluminium matrix (Fig. 4) are in high tension in the center of the specimen and decrease toward the surface. Superficial stress

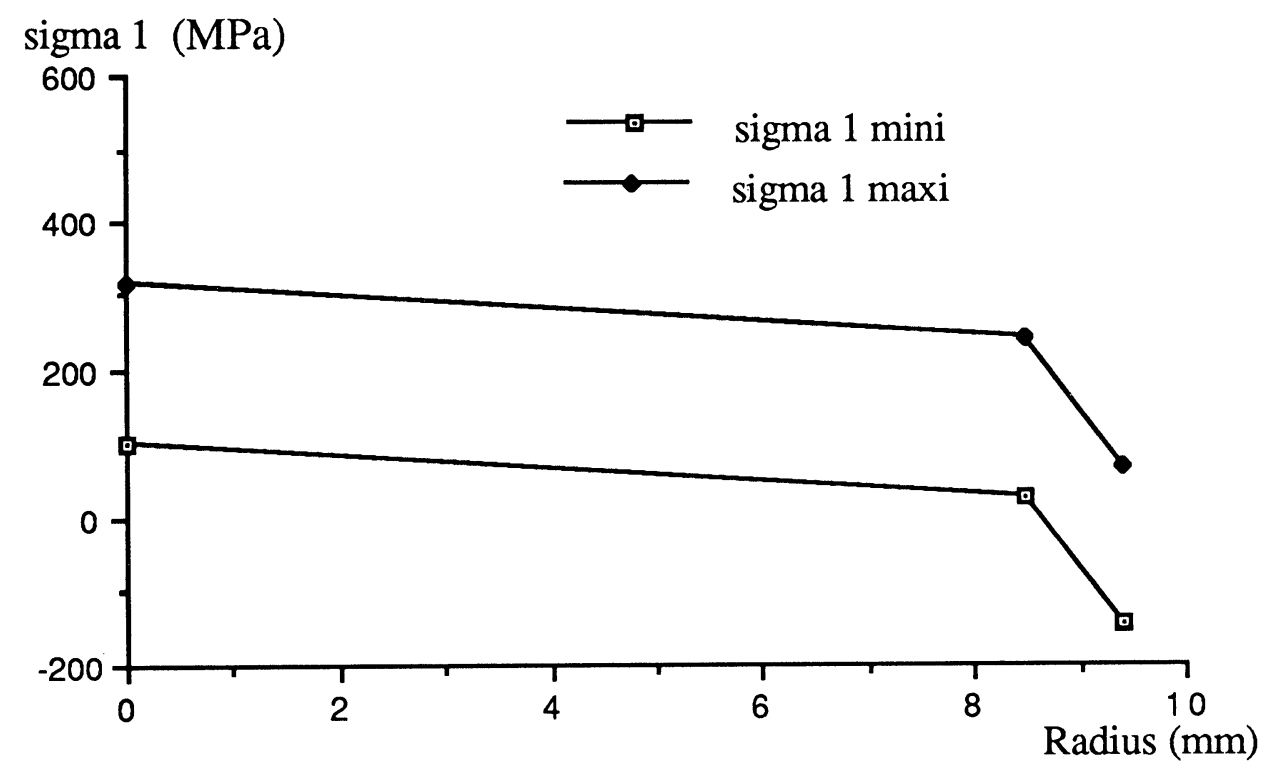

Fig. 3. $\sigma_{\theta}$ calculated with lowest and highest values of stress free parameter $a_{0}$.

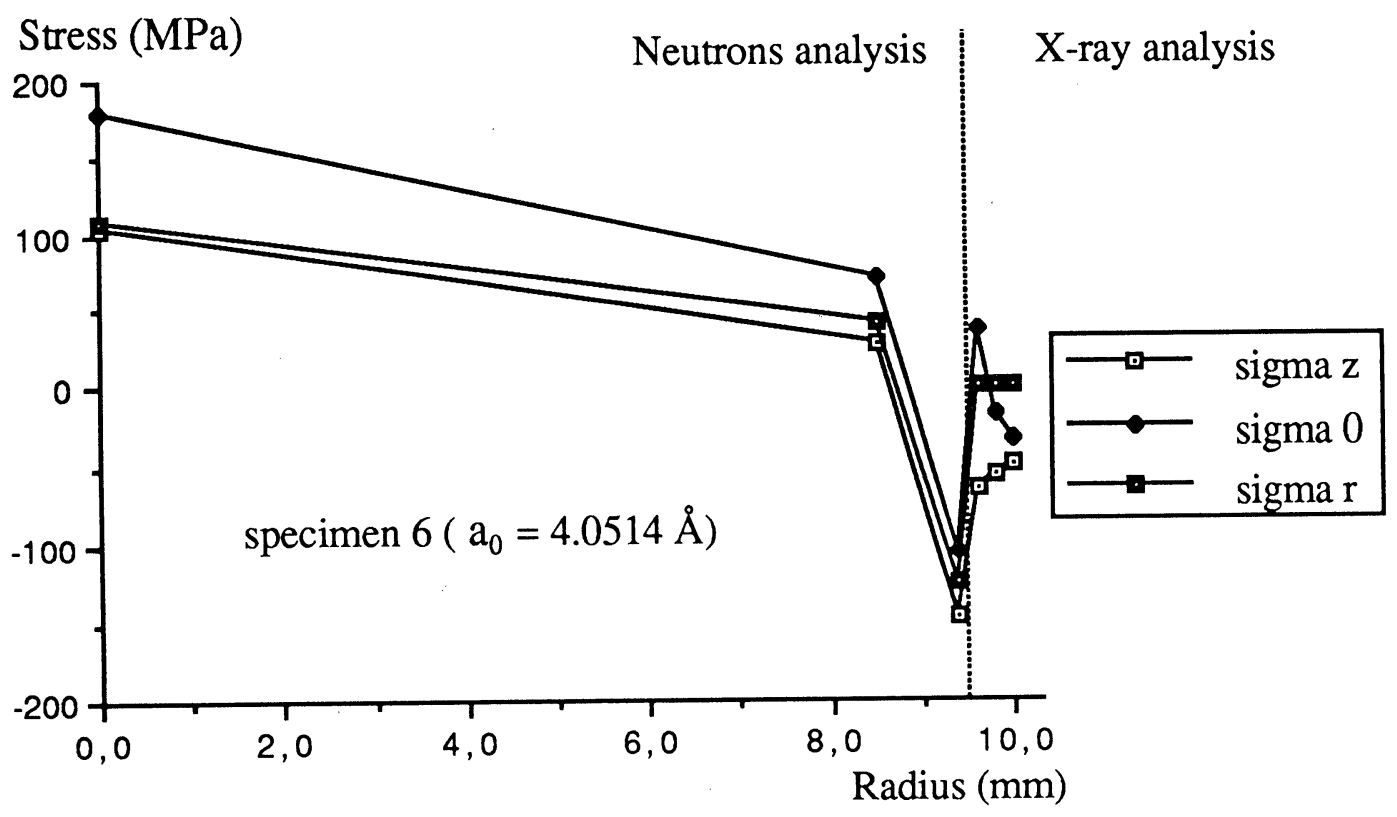

Fig. 4. Evolution of the axial, circonferential and radial stresses as a function of the radius for the MMC specimen. 
analysis carried out by X-ray diffraction (assuming $\sigma_{33}$ equal to zero) reveals low compressive values for $\sigma_{\Theta}$ and $\sigma_{z}$. In depth, on $0.5 \mathrm{~mm}$ removed by electropolishing, $\sigma_{\theta}$ remains almost constant and $\sigma_{z}$ increases and reach tensile values. There is a discrepancy between the last neutron analysis and these $\mathrm{X}$-ray values. This is due to the fact that on the rather large thickness analysed by neutron, there is both a change of $\mathrm{d}_{0}$ and of the stress components. We reach here a limit of the neutron method for which the thickness resolution is only of the order of $1 \mathrm{~mm}$. Without the X-ray information, it is not possible to point out this problem.

Only two 3D neutron measurements have been done in the $\mathrm{SiC}$ for $\mathrm{R}=0$ and $8.5 \mathrm{~mm}$. The accuracy is low. For $\mathrm{R}=0 \mathrm{~mm}$ there is a hydrostatic compression of -200 MPa. For $\mathrm{R}=$ $8.5 \mathrm{~mm}, \sigma_{\theta}=-100 \mathrm{MPa}, \sigma_{\mathrm{z}}=-1500 \mathrm{Mpa}, \sigma_{\mathrm{r}}=$ $-400 \mathrm{MPa}$. The ceramic phase is thus always in compression and interphase stresses may be very high.

For the pure 2024 specimen (Fig. 5), $\sigma_{\mathrm{r}}$ values is always smaller than $30 \mathrm{MPa}$. From the center to the surface $\sigma_{z}$ and $\sigma_{\theta}$ decrease from slight values to compression (-200 and -150$)$.

This evolution is qualitatively similar to that expected for such heat treatment stresses. ${ }^{11}$ This shape is also very similar to the $1^{\text {st }}$ order stresses that can be calculated for the MMC specimen by a combination of the stresses determined for $\mathrm{Al}$ and $\mathrm{SiC}$ phases by neutron diffraction at $\mathrm{r}=0$ and $8.5 \mathrm{~mm}$.

\section{CONCLUSION}

Neutron diffraction is very interesting tool to study residual stress distributions inside the specimens. The gradients of stresses and mainly of chemical composition (leading to a variation of the stress free parameter $a_{0}$ ) has to be very carefully studied because of the minimum thickness explored (about $1 \mathrm{~mm}$ in our case). Combination of X-ray and neutron experiments are very useful to clarify these problems.

First order stresses are similar between a pure $\mathrm{Al}$ alloy sample and an $\mathrm{Al}-\mathrm{SiC}$ sample.

Second order stresses in the MMC specimen are very high. They come from the differ-

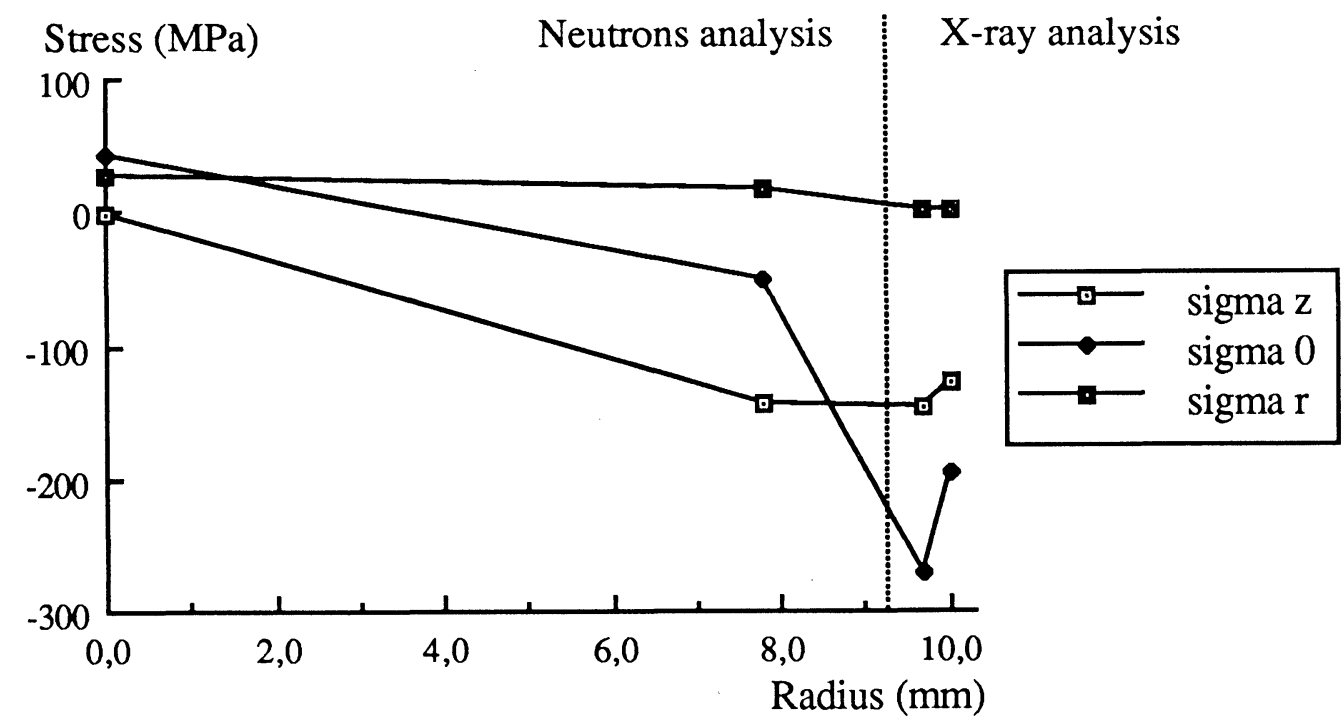

Fig. 5. Evolution of the axial, circonferential and radial stresses as a function of the radius for the $\mathrm{Al}$ alloy specimen. 
ences both the thermal expansion coefficients and the mechanical behaviour of $\mathrm{Al}$ matrix and $\mathrm{SiC}$.

\section{REFERENCES}

${ }^{1}$ H.J. Rack, Advanced Materials and Manufacturing Processing 3, 327(1988).

${ }^{2}$ H.M. Ledbetter, M.W .Austin, Materials Science and Engineering 89, 53(1987).

${ }^{3}$ V.C. Nardone, Scripta Metallurgica 20, 43(1986).

${ }^{4}$ S.D. Tsai, M. Scxhmerling, H.L. Marcus, 28th Sagamore Conference, Residual Stress and Stress Relaxation (Plenum Press, New York, 1981), pp.425438.

${ }^{5}$ T. Ericsson, J.L. Lebrun, P. Sainfort, B. Chenal, P. Jarry, Experimental study of residual macro and micro stresses in aluminium based composites, ICRS2(1988).

${ }^{6}$ V.I. Vladimirov, V.I. Monin, Physics and Metallic Metallurgy 44, 113(1979).
${ }^{7}$ T. Ericsson, J.L. Lebrun, P. Sainfort, B. Chenal, P. Jarry, 5th Scandinavian Symposium on Materials Science (1989).

${ }^{8}$ P.J. Withers, D.J. Jensen, H. Lilholt, W.M. Stobbs, Sixth International Conference on Composite Material and second European Conference on Composite Material, London - U.K. 2, (1987).

${ }^{9}$ A.J. Allen, M. Bourke, M.T. Hutchings, M.T. Krawitz, A.D. Windsor, Residual stresses in science and technology, Garmisk - Partenkircher 1, 151(1986)

${ }^{10} \mathrm{H}$. Lilht, D.J. Jensen, Proceeding of the Second International Conference on Testing, Evaluation and Quality Control of Composites, Guildford, England, 156(1987).

${ }^{11}$ G. Beck, T. Ericsson, Residual Stresses in Science and Technology, ICRS 1, Garmish - Partenkirche 1, 27 (1986).

This paper was presented in the International Satellite Conference on Mechanical Characterization of New Materials at Tokai University, July 19, 20, 1991. 